TAO, Supplementary Issue, 85-98, March 1999

\title{
The Scientific Project for ROCSAT-1/OCI
}

\author{
Hsien-Wen Li ${ }^{1}$, Chung-Ru Ho ${ }^{1}$, Nan-Jung Kuo ${ }^{1}$, Chun-Te Chen ${ }^{2}$,Tien-Shi Fang ${ }^{1}$, Wei-Peng Tsai ${ }^{1}$, \\ Tsan-Ming Lin ${ }^{1}$, Wen-Chen $\mathrm{Su}^{1}$, Leny-Hwa Leu ${ }^{1}$, Wei-Kang Hu${ }^{1}$ and Hong-Ann Chen ${ }^{1}$ \\ (Manuscript received 10 November 1998, in final form 22 January 1999)
}

\begin{abstract}
Taiwan's first scientific experimental satellite, ROCSAT-1, is scheduled to be launch in January 1999. It will carry three scientific payloads. One of them is an instrument named Ocean Color Imager (OCI) to monitor ocean colors. There are two major working groups for the scientific purpose of OCI, the Science Team (ST) and the Science Data Distribution Center (SDDC). The OCI-ST was formed for sensor calibration, atmospheric correction, algorithm development, and data validation. The OCI algorithms developed were tested by Sea-viewing Wide Field-of-view Sensor (SeaWiFS) data. The results show that the relative error of water-leaving radiance from OCI atmospheric correction algorithms is higher than that derived from SeaWiFS algorithms. However, the relative error of chlorophyll $a$ concentration derived from OCI bio-optical algorithm using the water-leaving radiance derived from OCI atmospheric correction algorithms is smaller than that for SeaWiFS products. Data from OCI will be processed and then distributed by the OCI-SDDC. The OCI-SDDC is also a day-to-day operations center. Anyone who is interested in OCI products can request them via the OCI-SDDC web site at http://www.oci.ntou.edu.tw/.
\end{abstract}

(Key words: Ocean color imager, ROCSAT-1, Science data distribution center, Science team, Ocean color, Remote sensing)

\section{INTRODUCTION}

After the launch of the first orbiting satellite in the early 1960s, it became clear that ocean color could be viewed from space in cloud free conditions. The color of the oceans could be blue, yellow, green, brown, or even red. Generally, the concentrations of phytoplankton, suspended matter or yellow substances may alter the color of the oceans. A change in ocean color means a change in concentrations of such materials near the sea surface and it may also relate to marine productivity and pollution. In coastal waters, for instance, abundant marine organisms, suspended solids and dissolved organic substances absorbing light cause the color of

\footnotetext{
${ }^{1}$ Department of Oceanography, National Taiwan Ocean University, Keelung, Taiwan, ROC

${ }^{2}$ Department of Fishery Science, National Taiwan Ocean University, Keelung, Taiwan, ROC
} 
water to change from the bluish region typical of clear ocean water to a yellowish color. Thus, the color of water in coastal waters is different from that in open oceans. From the remote sensing point of view, we mean that ocean color is the relative amounts of water-leaving radiance in various portions of the visible spectrum. Measurements of water-leaving radiance allow concentrations of pigment or chlorophyll $a$ to be derived. Therefore, ocean color maps are typically presented in a "false color" format that highlights this information. Because of the role of phytoplankton in the global carbon cycle, an understanding of its distribution and variability can help us to assess the role of the ocean ecosystem in global change. The distribution and variability of ocean color can also help the scientific community to study the dynamics of the oceans, the evolution of eddies, coastal currents and the physics of mixing. The success of the Coastal Zone Color Scanner (CZCS) in measuring the ocean color in the world's oceans has led to several proposals for follow-on systems. From the scientific perspective, acquisition of ocean color data from space in the 1990s is a high priority that has been recognized in reports of the National Research Council of the National Academy of Science, U.S.A. (Hooker et al., 1992).

Taiwan is scheduled to launch her first experimental satellite, ROCSAT-1, in early 1999. It weights a $400 \mathrm{~kg}$, and is a three-axis stabilized, low-earth orbit satellite with a $35^{\circ}$ inclination. ROCSAT-1 is designed to carry out three scientific experiments: ocean color imaging, ionospheric plasma and electrodynamics, and Ka-band communication. The payload instrument for ocean color imaging on ROCSAT-1 is called Ocean Color Imager (OCI). OCI has seven bands that span $443 \mathrm{~nm}$ to $865 \mathrm{~nm}$, and these are for mapping chlorophyll $a$ concentration distribution. The band characteristics are listed in Table 1. In order to have successful operation of OCI, there are two scientific groups under the OCI project, the Science Team (ST) and the Science Data Distribution Center (SDDC). The purpose of the ST is to calibrate the sensor, to correct for the atmospheric influence, to develop bio-optical algorithms, and to calibrate and validate OCI data. The ST working group participants are shown in Table 2. The SDDC at National Taiwan Ocean University (NTOU) is responsible for processing OCI data and then distributing it to users.

\section{SCIENTIFIC OBJECTIVES}

The purposes of the OCI project are to obtain valid ocean color data of the low- latitude oceans, to process the data into meaningful biological parameters, and to make the data readily available to researchers. The data are expected to contribute to marine productivity research, the study of ocean dynamics, atmospheric aerosol investigation, and potential fishery application. Through the OCI project, we also expect to advance the scientific applications of ocean color data and to improve the technical capabilities required for data processing, management and analysis.

\section{MISSION OPERATIONS CONCEPT}

OCI will perform imaging at any time between 9:00 and 15:00 local time. The variation of OCI latitude coverage for 9:00 to 15:00 is shown in Figure 1. Dark current calibration will be 
Table 1. Comparison of characteristics among CZCS, SeaWiFS, and OCI.

\begin{tabular}{|c|c|c|c|}
\hline & CZCS & SeaWiFS & OCI \\
\hline Inclination & $99.3^{\circ}$ & $98.25^{\circ}$ & $35^{\circ}$ \\
\hline Altitude $(\mathrm{km})$ & 955 & 705 & 600 \\
\hline Period (min) & 104.9 & 98.9 & 96.6 \\
\hline Orbital repeat time (days) & 6 & 16 & 52 \\
\hline Spectral bands (nm) & $\begin{array}{ll}\text { B1 } & 433-453 \\
\text { B2 } & 510-530 \\
\text { B3 } & 540-560 \\
\text { B4 } & 660-680 \\
\text { B5 } & 700-800\end{array}$ & $\begin{array}{ll}\text { B1 } & 402-422 \\
\text { B2 } & 433-453 \\
\text { B3 } & 480-500 \\
\text { B4 } & 500-520 \\
\text { B5 } & 545-565 \\
\text { B6 } & 660-680 \\
\text { B7 } & 745-785 \\
\text { B8 } & 845-885\end{array}$ & $\begin{array}{ll}\text { B1 } & 433-453 \\
\text { B2 } & 480-500 \\
\text { B3 } & 500-520 \\
\text { B4 } & 545-565 \\
\text { B5 } & 660-680 \\
\text { B6 } & 845-885 \\
\text { B7 } & 545-565\end{array}$ \\
\hline Nadir pixel $\left(\mathrm{m}^{2}\right)$ & $825 \times 825$ & $1130 \times 1130$ & $800 \times 800$ \\
\hline Swath width $(\mathrm{km})$ & 1636 & 2801 & 702 \\
\hline Redundancy & No & No & $555 \mathrm{~nm}$ \\
\hline Color sensing & Scanner & Scanner & push broom \\
\hline $\begin{array}{l}\text { Crossing equator time } \\
\text { (local time) }\end{array}$ & $12: 00$ & $12: 00$ & $9: 00 \sim 15: 00$ \\
\hline Bits & 8 & 10 & 12 \\
\hline Tilt & $-20^{\circ}, 0^{\circ}, 20^{\circ}$ & $-20^{\circ}, 0^{\circ}, 20^{\circ}$ & no \\
\hline Launch date (year/month) & $1978 / 10$ & $1997 / 8$ & $1999 / 1$ \\
\hline
\end{tabular}

performed during eclipse once a month for individual dark current reading checkout. The duration of dark current reading checkout will be about $20 \mathrm{sec}$.

The normal mission operation of OCI is to map ocean surface pigments whenever weather permits. Ideally, OCI will acquire ocean surface pigment data when cloud coverage is less 
Table 2. OCI-ST working group participants.

\begin{tabular}{ll}
\hline Working Item & \multicolumn{1}{c}{ Participant } \\
\hline Sensor Calibration & Wei-Song Lin (National Taiwan University) \\
Atmospheric Correction & $\begin{array}{l}\text { Gin-Rong Liu (National Central University) } \\
\text { A.-J. Chen (National Central University) } \\
\text { Wann-Jin Chen (Chung-Cheng Institute of Technology) } \\
\text { Chung-Yi Tseng (Academia Sinica) }\end{array}$ \\
& $\begin{array}{l}\text { Chun-Te Chen (National Taiwan Ocean University) } \\
\text { Bio-optical Algorithm }\end{array}$ \\
& $\begin{array}{l}\text { Tien-Shi Fang (National Taiwan Ocean University) } \\
\text { Data Validation }\end{array}$ \\
& $\begin{array}{l}\text { Chung-Ru Ho (National Taiwan Ocean University) } \\
\text { Nan-Jung Kuo (National Taiwan Ocean University) }\end{array}$ \\
\hline
\end{tabular}

than $50 \%$ of the area along the track. A secondary optional mission, land imaging, will be done only with selected spectral bands. The actual OCI operation will ultimately be decided by the OCI-ST. A preliminary operation priority has been established based on geographic locations, request sequences, weather conditions, and cross calibration and field validation areas. Any glimpse of Taiwan and its surrounding areas (such as South China Sea, East China Sea, Japan Sea, and Pacific Ocean) are all considered. Meanwhile, the other areas (such as Atlantic and Indian Oceans) can also be chosen with minor priority. Prescribed requests are considered first. In the case of an emergency request, that request will override the one prescribed. Cloud coverage should be less than $50 \%$ within the time of less sun glint. For calibration and validation purposes, image are scheduled to be taken when the OCI tracks overlap with SeaWiFS (Sea-viewing Wide Field-of-view Sensor) or other ocean color sensors, or the calibration buoy location or location of the experimental cruises.

The most important factor in OCI operations planning is the timing of image collection operations. The position and attitude of the spacecraft govern the target of image collection. A given ground target is determined by whether the spacecraft will pass over the location at an attitude which will allow OCI to acquire the image. The timing of operations is further restricted by the requirement that imaging can only be performed between 9:00 and 15:00 local time, which may also be subject to unfavorable weather conditions and the condition of the spacecraft.

The OCI SDDC will provide the start and stop times, the intended imaging mode, and any desired gain selections for uplink as stored commands. A calibration operation will be sched- 


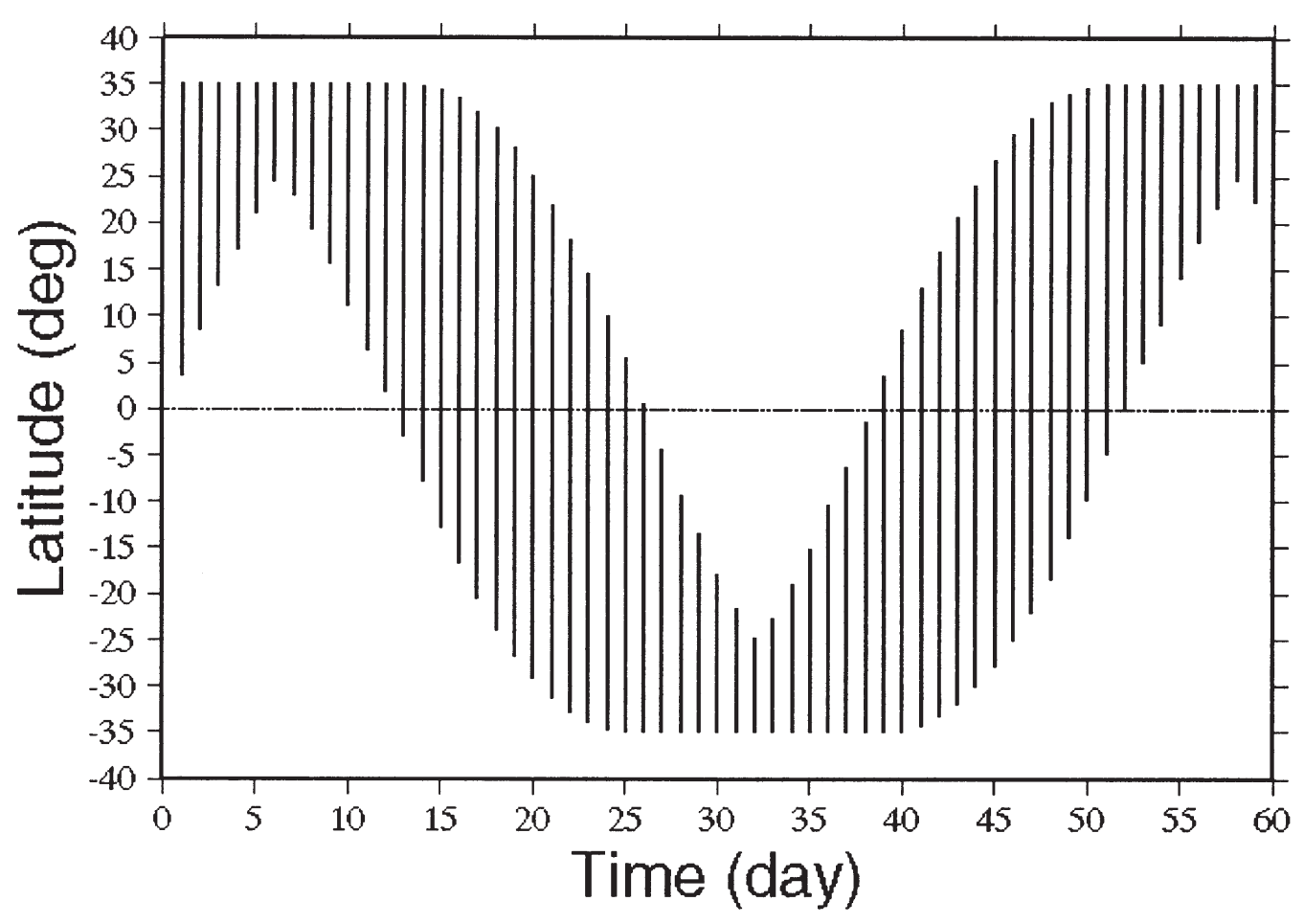

Fig. 1. Latitude coverage of OCI between 9:00 and 15:00 in a cycle.

uled once a week. For calibration, OCI will be operated in calibration mode. OCI does not broadcast and only one RGS (ROCSAT-1 Ground Segment) can the OCI data be downloaded. The data taken by OCI have to store in the Solid State Recorder (SSR) on ROCSAT-1 before they download to the RGS in Taiwan. Due to the limitation of SSR storage and the downlink time with RGS in Taiwan, imaging operations will generally be limited to approximately a 3\% duty cycle. This is equivalent to about two $702 \times 702 \mathrm{~km}$ square images per orbit, or about thirty images per day. Therefore, between zero to three images will be scheduled each orbit.

\section{CALIBRATION AND VALIDATION}

It is believed that the OCI calibration at each wavelength will change in some unpredictable manners as a function of time. Experience with previous sensors, such as CZCS or Advanced Very High Resolution Radiometer (AVHRR), has shown that it is very difficult to determine a sensor's calibration once it has been launched (Mueller and Austin, 1992). Unlike the SeaWiFS instrument, OCI has no on-board solar calibrator. Therefore, a cross-calibration program has to be performed.

As OCI crosses a given ocean at a selected local time, image data can be used to compare with the information from other instruments, such as SeaWiFS. A frequency of occurrence for 
orbit overlaps will be arranged. This type of symbiotic inter-instrument calibration activities near Taiwan waters is under consideration. However the cross-calibration method is not good enough because of the uncertainty of sensors. Therefore, a vicarious calibration method is employed in accordance with the cross-calibration method. The general concept of the vicarious calibration is as follows. First, following the launch the calibration is initialized by forcing agreement between the OCI determined radiance and the surface measurements under clear atmospheric conditions. Second, the algorithms are applied to other scenes characterized by bio-optical surface measurements and the calibration is adjusted until the measured waterleaving radiances are reproduced. Finally, the field measurements of chlorophyll $a$ are combined with OCI chlorophyll $a$ estimates, and the radiance calibration is fine tuned until the best agreement is obtained between the retrieved and true chlorophyll $a$ values.

\subsection{Atmospheric Correction Algorithms}

To have validated OCI data, the atmospheric correction plays an important role. The radiance measured by a satellite sensor includes the water-leaving radiance backscattered out from the water surface, and the solar radiance scattered by the atmosphere and reflected by the sea surface. According to the assumptions of CZCS and SeaWiFS, the total measured radiance, $L_{t}$, can be assumed to be the summation of the contributions from Rayleigh scattering, $L_{r}$, aerosol scattering, $L_{a}$, the direct solar radiance reflected from the sea surface, $L_{g}$, and water leaving radiance, $L_{w}$, and can be written as

$$
L_{t}=L_{r}+L_{a}+L_{g}+T L_{w}
$$

where $T$ is the direct transmittance through the atmosphere. The task of the atmospheric correction is to extract $L_{w}$, given $L_{t}$. Figure 2 shows the flow chart for the atmospheric correction of OCI (Liu and Chen, 1998). Before making the atmospheric correction, land and cloud masking will first be performed. The total radiance of the $865 \mathrm{~nm}$ band of OCI will be used to mask the land and cloud area. Meanwhile, OCI does not have a tilting mechanism to avoid sun glint. Therefore, the pixel data will be useless due to sun glint contamination where the probability parameter for sun glint is greater than 1.5 (McClain and Yeh, 1994). Cox and Munk (1954a, 1954b) estimated the slope distribution of ocean wave surface by using a statistic model. Viollier et al. (1980) assumed that the wave surface direction is a Gaussian distribution and that its slope is a function of wind speed only. Their assumption will be used to calculate the sun glint. The single scattering method (Eckstein and Simpson, 1991) is used to calculate the Rayleigh scattering radiance, and the aerosol scattering radiance from Gordon and Castano (1987) is adopted in this study.

\subsection{Field Measurements of Optical Properties}

To validate the results of $\mathrm{OCI}$ atmospheric correction, field measurements of optical properties are performed with a Tethered Spectral Radiometer Buoy (TSRB-II) and a SeaWiFS 


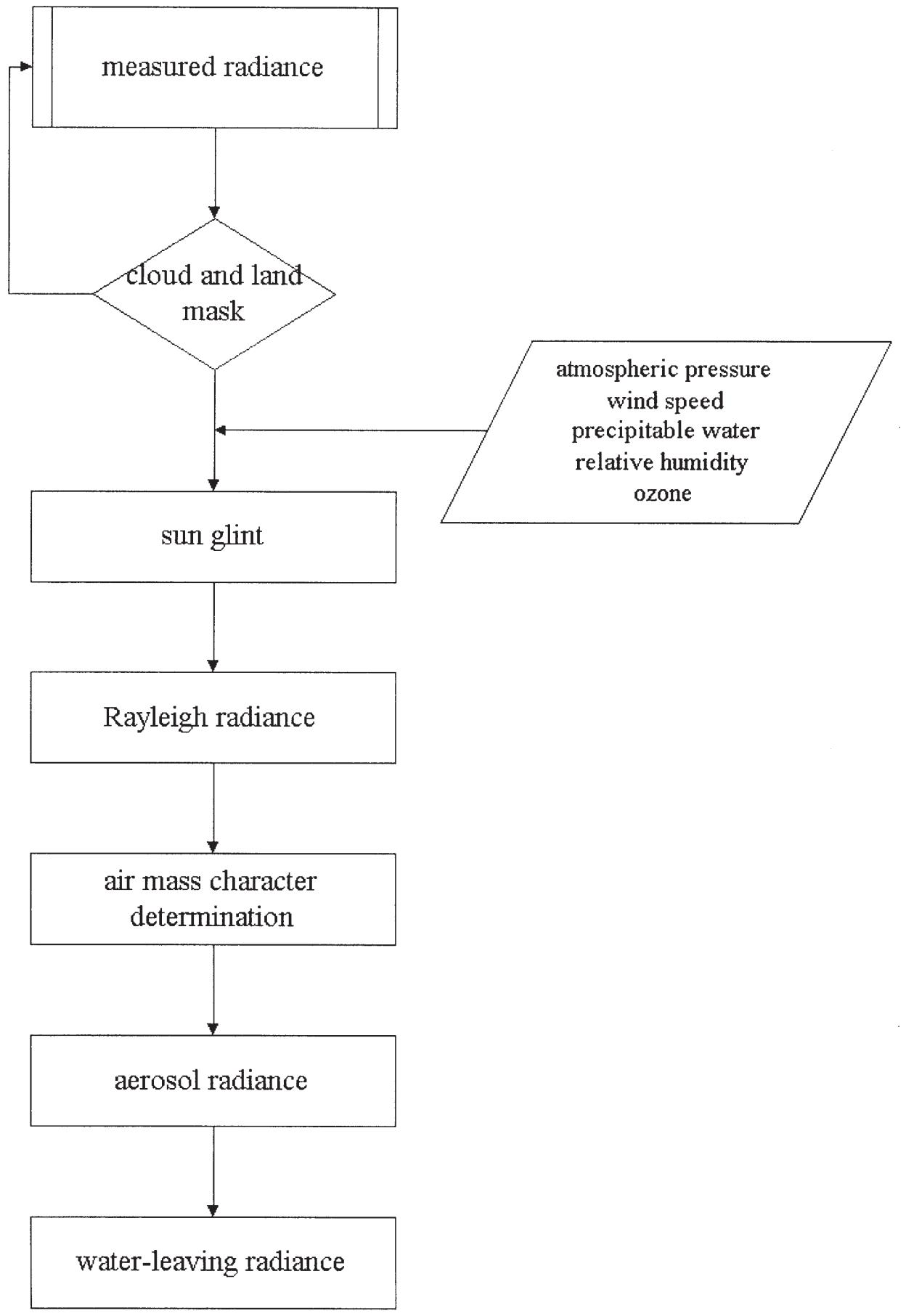

Fig. 2. OCI atmospheric correction procedure. 
Profiling Multichannel Radiometer (SPMR) made by Satlantic Company. TSRB-II is an optical buoy, which can measure the in-water upwelling radiance just beneath the sea surface $L_{u}\left(0^{-}, \lambda\right)$ and the incident spectral irradiance above the sea surface $E_{S}(\lambda)$. SPMR is a profiling radiometer that can measure the in-water upwelling radiance $L_{u}(Z, \lambda)$ and downwelling spectral irradiance $E_{d}(Z, \lambda)$ with depth $Z$.

To obtain $L_{w}(\lambda)$ that is measured by the OCI it is necessary to propagate $L_{u}\left(0^{-}, \lambda\right)$ upward through the sea surface as

$$
L_{w}\left(0^{+}, \lambda\right)=L_{u}\left(0^{-}, \lambda\right) \frac{1-\rho(\lambda, \theta)}{n_{w}^{2}(\lambda)}
$$

where $\rho(\lambda, \theta)$ and $n_{w}(\lambda)$ are the Fresnel reflectance at the solar Zenith angle $\theta$ and the refractive index for seawater, respectively. In order to remove the influence of view angle, sun angle and the solar irradiance, the water-leaving radiance is generally transferred to normalized water-leaving radiance $L_{w n}$ as

$$
L_{w n}(\lambda)=L_{w}(\lambda) \frac{\overline{F_{0}}(\lambda)}{E_{S}(\lambda)}
$$

where $\bar{F}_{0}(\lambda)$ denotes the mean extraterrestrial solar irradiance (Neckel and Labs,1984).

\subsection{Bio-optical Algorithms}

Since the band characteristics of OCI are similar to those of SeaWiFS, some of the algorithms derived for SeaWiFS by previous studies (Gordon, 1990; Aiken et al., 1995) are evaluated using the data sets that are collected in the water adjacent to Taiwan. The evaluated algorithms are listed in Table 3 and include both semi-analytical and empirical methods. We have collected more than 150 in-situ data sets that include optical properties and water samples in order to derive the relationship between optical properties and chlorophyll $a$ concentration. All samples, except the surface seawater, were collected by Go-Flo 2.5/5 L sampler which was attached on the rosette multi-sampler. Surface seawater was collected with a bucket. One liter of seawater was immediately filtered by Whatman $\mathrm{GF} / \mathrm{F}(25 \mathrm{~mm})$ filter, under pressure $(<0.2$ bar). To determinate of chlorophyll $a$ concentration, the filtered sample was frozen in liquid nitrogen on board, while in the laboratory the N, N-dimethylformamide (DMF) extracting solvent was added in darkness at $-20^{\circ} \mathrm{C}$. Compared with the acetone extracting solvent, DMF has some advantages (Suzuki and Fujita, 1986; Porra et al., 1989; Suzuki and Ishimaru, 1990) and was therefore used in this study. The measurement of chlorophyll $a$ was undertaken in the laboratory according to the fluorescence method described by Strickland and Parsons (1972). From the correlation coefficient calculation and error analysis using the available field measurements for the water adjacent to Taiwan, we found that Gordon's (1990) method is recommended as the bio-optical algorithm for processing OCI data. However, the bio-optical algorithm may be changed when the real OCI data are available. 
Table 3. Bio-optical algorithms between chlorophyll a concentration $C$ and the ratio of normalized water-leaving radiance $L_{w n}$.

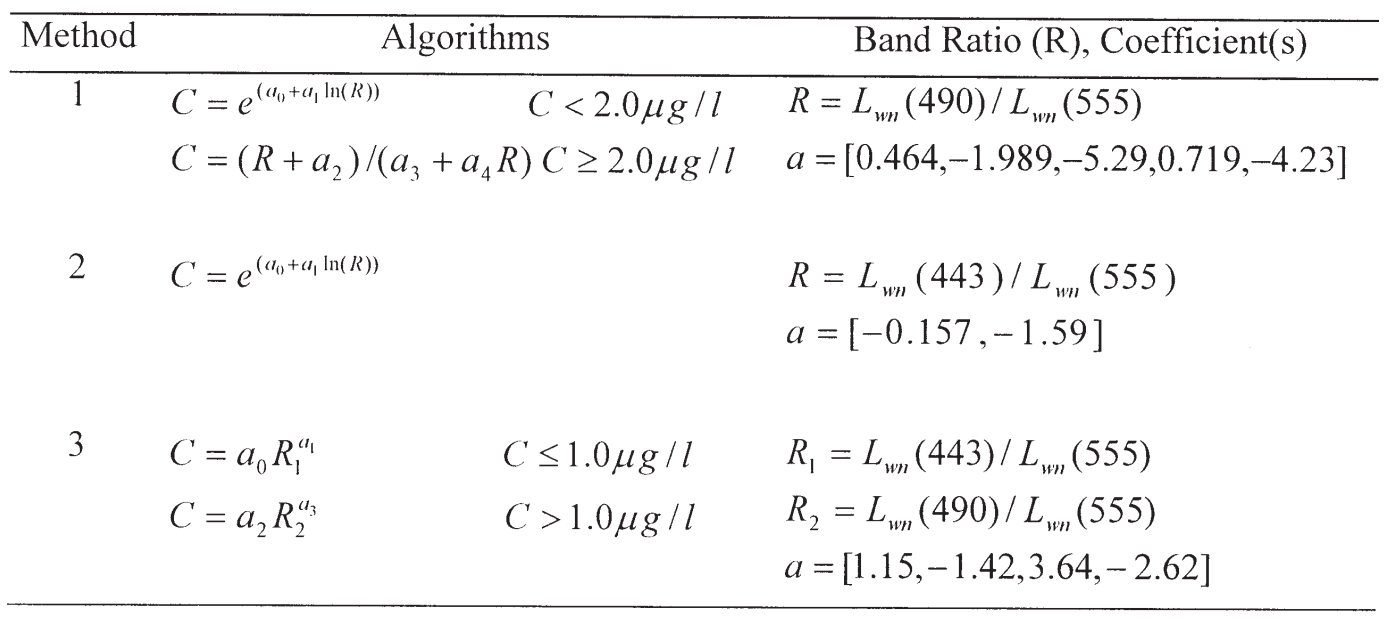

\subsection{Data Evaluation}

Six SeaWiFS data sets were used for evaluating the OCI atmospheric correction algorithm and the OCI bio-optical algorithm. The $L_{w n}$ measured by the TSRB-II and SPMR is used as the standard for comparison with that derived from the OCI atmospheric correction, and that derived from SeaDAS. SeaDAS is a software package for processing SeaWiFS data. The results of $L_{w n}$ for $412 \mathrm{~nm}, 443 \mathrm{~nm}, 490 \mathrm{~nm}, 510 \mathrm{~nm}$, and $555 \mathrm{~nm}$ are listed in Table 4. The chlorophyll $a$ concentration determined from water samples in the laboratory using fluorometric method is also considered as the standard chlorophyll $a$ concentration for comparison with those derived from the OCI bio-optical algorithm and from SeaDAS. The results of comparison are also shown in Table 4. The relative error $R E$ is used to examine the variances of OCI and SeaWiFS models with in-situ measurements. The $R E$ is defined as

$$
R E=\sqrt{\frac{\sum_{i=1}^{n}\left(x_{f i}-x_{m i}\right)^{2}}{n}}
$$

where $x_{f i}$ is the value of field measurements and $x_{m i}$ is the result derived from OCI algorithms or SeaWiFS algorithms, and $n$ is the total number of testing samples. This result is also listed in Table 4. From the result of relative error analysis, we can find that $L_{w n}$ derived from the OCI atmospheric correction is higher than that derived from SeaDAS. However, the relative error of chlorophyll $a$ concentration derived from the OCI algorithm is smaller than that derived from the SeaWiFS algorithm. From comparison of the results, we can conclude that the atmospheric correction algorithm and bio-optical algorithm for OCI can obtain the same quality as SeaWiFS algorithms from SeaWiFS data. 
Table 4. Comparison of Lwn and chlorophyll a concentration among field measurements, OCI algorithm results, and SeaDAS results.

\begin{tabular}{|c|c|c|c|c|c|c|c|c|}
\hline \multirow[t]{2}{*}{ Method } & \multicolumn{2}{|c|}{ Location } & \multicolumn{5}{|c|}{$L_{w n}\left(\mu \mathrm{m} / \mathrm{cm}^{2} \mathrm{~nm} \mathrm{sr}\right)$} & \multirow{2}{*}{$\begin{array}{c}\text { Chlorophyll } a \\
(\mu \mathrm{g} / 1)\end{array}$} \\
\hline & Lat. & Lon. & 412 & 443 & 490 & 510 & 555 & \\
\hline In-situ & $24.46^{\circ}$ & $121.85^{\circ}$ & 1.18 & 1.01 & 0.89 & 0.61 & 0.30 & 0.30 \\
\hline OCI & $24.47^{\circ}$ & $121.90^{\circ}$ & 1.11 & 1.12 & 0.85 & 0.52 & 0.32 & 0.19 \\
\hline SeaDAS & $24.47^{\circ}$ & $121.90^{\circ}$ & 1.54 & 1.32 & 1.04 & 0.55 & 0.24 & 0.08 \\
\hline In-situ & $24.50^{\circ}$ & $122.01^{\circ}$ & 1.52 & 1.32 & 1.00 & 0.58 & 0.24 & 0.14 \\
\hline OCI & $24.50^{\circ}$ & $121.98^{\circ}$ & 1.10 & 1.30 & 0.82 & 0.48 & 0.21 & 0.09 \\
\hline SeaDAS & $24.50^{\circ}$ & $121.98^{\circ}$ & 1.26 & 1.16 & 0.89 & 0.44 & 0.14 & 0.02 \\
\hline In-situ & $24.15^{\circ}$ & $121.70^{\circ}$ & 1.00 & 0.93 & 0.89 & 0.60 & 0.29 & 0.31 \\
\hline OCI & $24.15^{\circ}$ & $121.70^{\circ}$ & 0.83 & 1.02 & 0.86 & 0.68 & 0.40 & 0.30 \\
\hline SeaDAS & $24.15^{\circ}$ & $121.70^{\circ}$ & 0.82 & 0.93 & 0.87 & 0.63 & 0.30 & 0.21 \\
\hline In-situ & $24.07^{\circ}$ & $121.85^{\circ}$ & 1.36 & 1.14 & 0.97 & 0.62 & 0.28 & 0.25 \\
\hline OCI & $24.07^{\circ}$ & $121.85^{\circ}$ & 0.97 & 1.00 & 0.56 & 0.35 & 0.07 & 0.02 \\
\hline SeaDAS & $24.07^{\circ}$ & $121.85^{\circ}$ & 1.82 & 1.67 & 1.09 & 0.76 & 0.33 & 0.15 \\
\hline In-situ & $23.98^{\circ}$ & $122.00^{\circ}$ & 1.70 & 1.40 & 1.04 & 0.59 & 0.25 & 0.12 \\
\hline OCI & $23.98^{\circ}$ & $122.00^{\circ}$ & 0.95 & 1.05 & 0.78 & 0.54 & 0.34 & 0.24 \\
\hline SeaDAS & $23.98^{\circ}$ & $122.00^{\circ}$ & 1.40 & 1.29 & 0.89 & 0.51 & 0.18 & 0.05 \\
\hline In-situ & $23.87^{\circ}$ & $122.16^{\circ}$ & 2.32 & 1.85 & 1.28 & 0.71 & 0.29 & 0.08 \\
\hline $\mathrm{OCI}$ & $23.87^{\circ}$ & $122.16^{\circ}$ & 1.30 & 1.24 & 0.81 & 0.52 & 0.27 & 0.13 \\
\hline SeaDAS & $23.87^{\circ}$ & $122.16^{\circ}$ & 2.15 & 1.83 & 1.18 & 0.70 & 0.27 & 0.07 \\
\hline \multirow[t]{2}{*}{ Relative error } & \multicolumn{2}{|c|}{ OCI } & 0.57 & 0.30 & 0.29 & 0.15 & 0.11 & 0.12 \\
\hline & \multicolumn{2}{|c|}{ SeaDAS } & 0.34 & 0.29 & 0.13 & 0.10 & 0.07 & 0.13 \\
\hline
\end{tabular}




\section{DATA PROCESSING AND DATA OUTPUTS}

Data from the OCI instrument will be processed and then distributed by the SDDC. Scientists from universities and research institutions can request OCI data from SDDC via electronic network. Specifically, the SDDC is responsible for organizing the OCI user groups and for developing software that will be required for processing and analyzing the OCI data. During the mission operation phase, the SDDC is also a day-to-day mission operation and planning center. The functional architecture of the SDDC is shown in Figure 3.

After receiving OCI scientific data packets from the satellite, RGS/Science Control Center (SCC) at National Space Program Office (NSPO) will reconstruct them into OCI Level-0 data. The OCI Level-0 data flow containing the science data sent from the satellite and the header record added by RGS will be sent to SDDC. RGS will also generate orbit and attitude data flow for SDDC. The data flow contains the header, predicted Cartesian data, definitive Cartesian data, and predictive Keplerian data.

Upon receiving OCI Level-0 and ancillary data from SCC, the SDDC will perform data decoding and further processing to generate Level-1 data files and Quick-Look plots for monitoring instrument performance. Level-1 data sets are the Level-0 data set with the packet header removed, the gain and offset correction applied, and the location of the center pixel of each scan line added. Moreover, the SDDC will compile higher level OCI data sets according to various parameters in response to the requests of scientists and users. The OCI data products will include normalized water-leaving radiances of Band 1 to Band 4 and chlorophyll $a$ concentration maps.

Both during and after the mission operation phase, the SDDC will be responsible for storing, archiving, querying, and distributing the OCI data and algorithms. Furthermore, the SDDC and ST will actively communicate with the research and education communities to promote the maximum usage of OCI data.

\section{CONCLUSIONS}

ROCSAT-1 is Taiwan's first scientific experimental satellite and it will carry an ocean color sensor to monitor ocean colors. The OCI-ST and OCI-SDDC are responsible for preparing quality OCI data and making them available. The OCI-ST used SeaWiFS data to simulate OCI data and applied the algorithms developed by OCI-ST to simulation data. The results show that OCI data have almost the same quality as SeaWiFS data and that the algorithms developed for OCI work well. In order to contribute to the international scientific communities, OCI data are free to the scientific or educational users of the world. OCI data products will include normalized water-leaving radiance and chlorophyll $a$ concentration. The updated information and data policy of OCI are also available on the OCI web site at http:// www.oci.ntou.edu.tw/.

Acknowledgments Many thanks go to the captain and crew of R/V Ocean Researcher II and R/V Ocean Researcher III for shipboard assistance. We appreciate the assistance of the GSFC/ DAAC of NASA for providing the SeaWiFS data. We also thank Ms. C.-F. Lin and Ms. H.-H. 


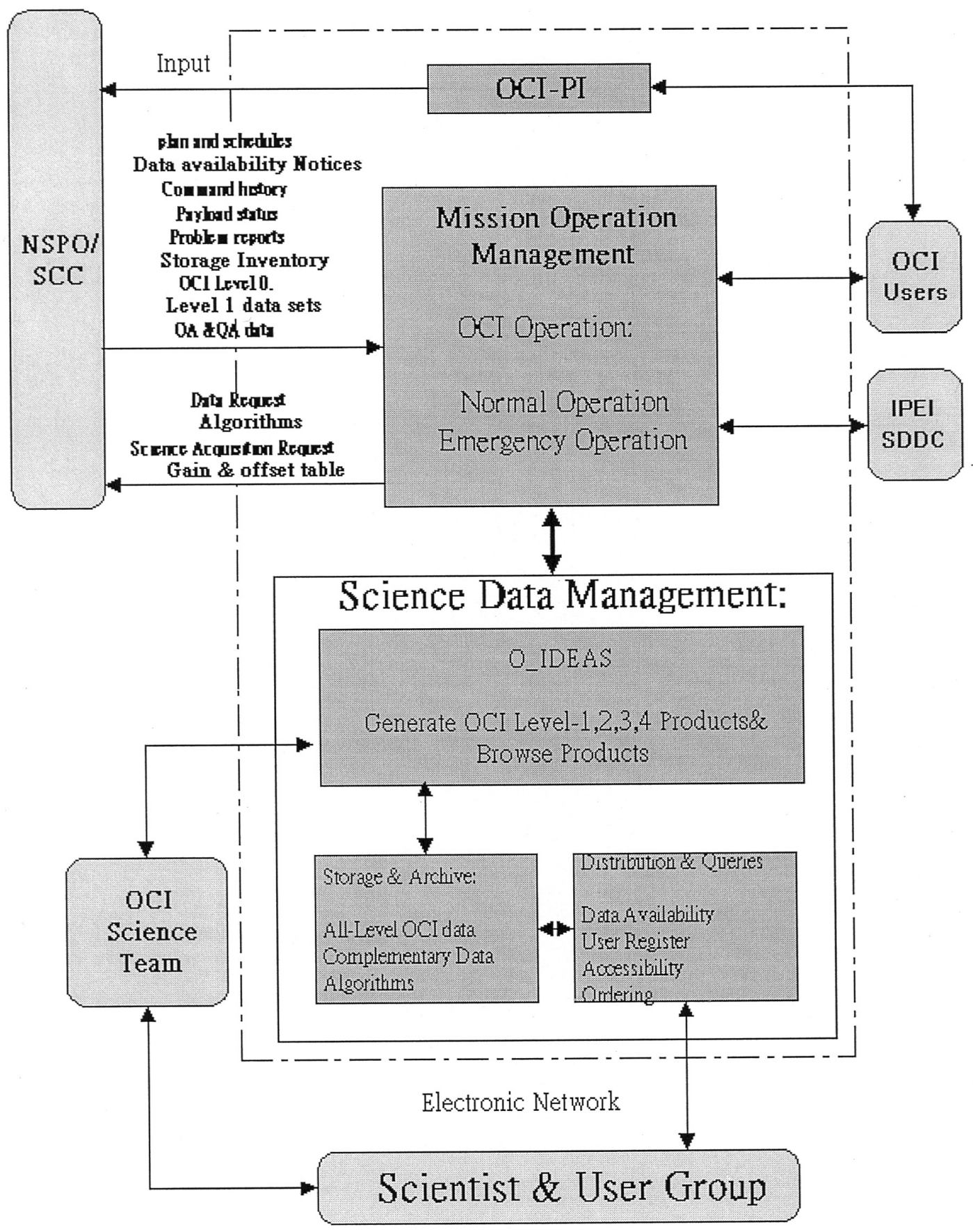

Fig. 3. OCI SDDC function architecture. 
Huang for preparing figures and typing the manuscript. This work is supported by the NSPO under grants NSC83-NSPO-A-RDD-019-002, NSC84-NSPO-(A)-OCI-001-02, NSC85-NSPO(A)-OCI-019-02, NSC86-NSPO-(A)-OCI-019-01, NSC86-NSPO-(A)-OCI-019-02, NSC87NSPO-(A)-OCI-019-01, NSC87-NSPO-(A)-OCI-019-02, NSC88-NSPO-(A)-OCI-019-01, and NSC88-NSPO-(A)-OCI-019-02.

\section{REFERENCES}

Aiken, J., G. F. Moore, C. C. Trees, S. B. Hooker and D. K. Clark, 1995: The SeaWiFS CZCS type pigment algorithm. NASA Tech. Memo. 104566, Vol.29.

Cox, C. and W. Munk, 1954a: Measurement of the roughness of the sea surface from photographs of the sun's glitter. J. Opt. Soc. Am., 44, 838-850.

Cox, C. and W. Munk, 1954b: Statistics of the sea surface derived from sun glitter. J. Mar. Res., 13,198-277.

Eckstein, B. A. and J. J. Simpson, 1991: Aerosol and Rayleigh radiance contributions to coastal zone color scanner images. Int. J. Remote Sensing, 12, 135-168.

Gordon, H. R., 1990: Radiometric considerations for ocean color remote sensors. Applied Optics, 29, 3228-3236.

Gordon, H. R., 1993: Radiative transfer in the atmosphere for correction of ocean color remote sensors. In: Barale and Schlittenhardt (Eds.), Ocean Colour: theory and applications in a decade of CZCS experience, Kluwer Academic, 33-78pp.

Gordon, H. R. and D. J. Castano, 1987: Coastal zone color scanner atmospheric correction algorithm: multiple scattering effects. Applied Optics, 26, 2111-2122.

Hooker, S. B., W. E. Esaias, G. C. Feldman, W. Gregg and C. R. McClain, 1992: An overview of SeaWiFS and ocean color. NASA Tech. Memo. 104566, Vol. 1.

Liu, G.-R. and A. Chen, 1998: Atmospheric correction model of OCI remote sensing channels (II), 1998 OCI Science Team Report, 66pp.

McClain, C. R. and E. N. Yeh, 1994: Sun Glint Flag Sensitivity Study. NASA Tech. Memo. 104566, Vol. 13.

Mueller, J. L. and R. W. Austin, 1992: Ocean optics protocols for SeaWiFS validation. NASA Tech. Memo. 104566, Vol. 5.

Neckel, H. and D. Labs, 1984: The solar radiation between 3,300 and 12,500 A. Solar Phys., 90, 205-258.

Porra, R. J., W. A. Thompson and P. E. Kriedemann, 1989: Determination of accurate coefficients and simultaneous equations for assaying chlorophylls $a$ and $b$ extracted with four different solvents: verification of the concentration of chlorophyll standards by atomic absorption spectroscopy. Biochem. Biophys. Acta, 975, 384-394.

Strickand, J. D. H. and T. R. Parsons, 1972: A practical handbook of sea water analysis. Fisheries Research Board of Canada, Vol. 167, 310pp.

Suzuki, R. and Y. Fujita, 1986: Chlorophyll decomposition in Skeletonema costatum: a problem in chlorophyll determination of water samples. Mar. Ecol. Prog. Ser., 28, 81-85.

Suzuki, R. and T. Ishimaru, 1990: An improved method for the determination of phytoplanktion 
chlorophyll using N, N-Dimethylformamide. J. Oceanogr. Soci. Japan, 46, 190-194.

Viollier, M., D. Tanre and P. Y. Deschamps, 1980: An algorithm for remote sensing of water color from space. Boundary-Layer Meteorology, 18, 247-267. 